\title{
Critics of Near-Death Experiences as Evidence for Survival: A Methodological Note
}

To the Editor:

There has been a great deal of popular and scholarly writing arguing that near-death experiences (NDEs) are evidence for life after death. Although there has been a great deal of research on NDEs, much of the research is methodologically unsound. Samples are neither randomly chosen nor complete samples of circumscribed populations. The NDEs reported by subjects typically occurred years before the research and are, therefore, subject to memory distortion.

The most common tactic of critics of the proposition that NDEs are evidence for life after death is to describe an alternative phenomenon and claim that NDEs are simply examples of this phenomenon. For example, one of the drugs suggested as inducing experiences similar to NDEs is ketamine. Ketamine appears to block the receptors in the brain whose functioning is controlled by the neurotransmitter glutamate. Karl Jansen (1997) claimed that ketamine experiences and NDEs are similar. Here is one account of a ketamine-induced hallucination, 
reported by an anesthesiologist:

... My first memory is of colors. I saw red everywhere, then a yellow square on the left grew and crowded out the red. My vision faded, to be replaced with a black-and-white checkerboard which zoomed to and from me. More patterns appeared and faded, always in focus, with distinct edges and bright colors.

Gradually I realized my mind existed and I could think. I wondered, "What am I?" and "Where am I?" I had no consciousness of existing in a body; I was a mind suspended in space. At times I was at the center of the earth, in Ohio (my former home), on a space-ship or in a small brightly-colored room without doors or windows. I had no control over where my mind floated. Periods of thinking alternated with pure color hallucinations. (Johnstone, 1973, p. 461)

This description does not resemble the NDE. I think it highly probable that quantitative research comparing the two types of experience would find them to be quite different.

Russell Noyes and Roy Kletti (1976) claimed that NDEs are examples of depersonalization experiences. K. Davidson (1964) provided descriptions from people who had undergone episodic depersonalization experiences. One patient

complains of feeling in a trance, detached from his surroundings which appear unreal, and other people seem odd and unnatural. The most distressing symptom is a feeling that his head had entirely disappeared, leaving only his eyes protruding on stalks. He feels he is going mad, and ruminates on the possibility of having damaged his brain. During his attacks, he is restless, unable to concentrate and unable to work and appears depressed. (Davidson, 1964, p. 507)

\section{Another patient}

describes the sensation as "like being in another world", "time has no meaning", "as though I am dead". In some of the attacks he experiences an unpleasant smell for approximately five minutes which reminds him of an occasion when his car radiator boiled dry. At other times his fingers feel greatly enlarged. (Davidson, 1964, p. 507)

These are quite different from the prototypical NDE.

Let me present one final example. James Whinnery (1997) suggested that those who are put in gravity accelerators such as a centrifuge and lose consciousness have an experience similar to an NDE. Here are two reports of this experience:

I was floating on a blue ocean, on my back ... kind of asleep but not asleep. I knew the sun was up... like someone was trying to wake me up. Finally, I woke up and I was on the centrifuge! I did not want to 
wake up... I could see myself on the water and also look at the sun; the sky was very blue, the sun very yellow. (Whinnery, 1997, p. 246)

I was in the grocery store going down one of the aisles. I was ... being propelled by something like a magic carpet, although I could not make movements. I wanted to reach out and get a carton of ice cream but could not move my arm or even my eyes to look for it. It was intensely frustrating to hear the warning horn and not be able to get my arm down to turn the darn thing off. (Whinnery, 1997, p. 246).

Again, these do not resemble the prototypical NDE.

Although the research conducted by those who argue that NDEs are evidence for life after death is often methodologically poor, the critics of this position have published no research. The critics have proposed alternative theories and have claimed that their theories are correct, but none of the critics has conducted research to show that the phenomena they propose are identical to NDEs are in fact identical. I write this with certainty, having recently completed a thorough review of the relevant literature on the topic for a forthcoming book.

Let us see what we need to resolve these issues. Consider the hypothesis that NDEs are the same as depersonalization experiences. We need, then, 100 reports of NDEs and 100 reports of depersonalization experiences. These reports need to be collected in the same way. NDEs are usually related to the investigator months or years after the experience. In this case, either the depersonalization experiences must be collected under identical conditions, that is, the same number of months and years after the experience, or, preferably, both the near-death and depersonalization experiences have to be collected immediately after the time of the experience.

Next, one team of investigators must examine 50 of the NDEs while another team examines 50 of the depersonalization experiences, in order to decide upon what are the basic elements of the experience. Each time must produce a checklist of these elements.

Next, these elements are combined into one list and randomized. Then a third team read the remaining 100 reports of experiences- 50 NDEs and 50 depersonalization experiences, randomly arranged-and completes the checklist for each of the 100 reports. Finally, a statistician explores whether the two sets of 50 reports differ.

The next study would be to find new samples of those who have NDEs and depersonalization experiences and have these individuals complete the same checklist for their experiences. Our statistician can then explore whether the two sets of checklists differ. 
This has never been done by any of the critics of the hypothesis that NDEs are evidence for life after death, nor indeed by those arguing in favor of the hypothesis! Until this is done, we cannot resolve these issues.

\section{References}

Davidson, K. (1964). Episodic depersonalisation. British Journal of Psychiatry, 110, 505513.

Johnstone, R. E. (1973). A ketamine trip. Anesthesiology, 39, 460-461.

Noyes, R., and Kletti, R. (1976). Depersonalization in the face of life-threatening danger. Psychiatry, 39, 19-27.

Whinnery, J. (1997). Psychophysiological correlates of unconsciousness and near-death experiences. Journal of Near-Death Studies, 15, 231-258.

David Lester, Ph.D.

Psychology Program

The Richard Stockton State College

P.O. Box 195

Jimmie Leeds Road

Pomona, NJ 08240-0195

e-mail: lesterd@stockton.edu 